\title{
Article
}

\section{The Natural Pigment Violacein Potentially Suppresses the Proliferation and Stemness of Hepatocellular Carcinoma Cells In Vitro}

\author{
Yu Jin Kim ${ }^{1,+}$, Nayeong Yuk ${ }^{2,+}$, Hee Jeong Shin ${ }^{1}$ and Hye Jin Jung ${ }^{1,2,3, *(D)}$ \\ 1 Department of Life Science and Biochemical Engineering, Sun Moon University, Asan 31460, Korea; \\ petaldew17@naver.com (Y.J.K.); gmlwjd903@naver.com (H.J.S.) \\ 2 Department of Pharmaceutical Engineering and Biotechnology, Sun Moon University, Asan 31460, Korea; \\ nayeong7249@naver.com \\ 3 Genome-Based BioIT Convergence Institute, Sun Moon University, Asan 31460, Korea \\ * Correspondence: poka96@sunmoon.ac.kr; Tel.: +82-41-530-2354; Fax: +82-41-530-2939 \\ + These authors contributed equally to this work.
}

Citation: Kim, Y.J.; Yuk, N.; Shin H.J.; Jung, H.J. The Natural Pigment Violacein Potentially Suppresses the Proliferation and Stemness of Hepatocellular Carcinoma Cells In Vitro. Int. J. Mol. Sci. 2021, 22, 10731. https://doi.org/10.3390/ijms 221910731

Academic Editor: Hidayat Hussain

Received: 24 July 2021

Accepted: 1 October 2021

Published: 3 October 2021

Publisher's Note: MDPI stays neutral with regard to jurisdictional claims in published maps and institutional affiliations.

Copyright: (c) 2021 by the authors. Licensee MDPI, Basel, Switzerland This article is an open access article distributed under the terms and conditions of the Creative Commons Attribution (CC BY) license (https:// creativecommons.org/licenses/by/ $4.0 /)$

\begin{abstract}
Hepatocellular carcinoma (HCC) is a malignant type of primary liver cancer with high incidence and mortality, worldwide. A major challenge in the treatment of HCC is chemotherapeutic resistance. It is therefore necessary to develop novel anticancer drugs for suppressing the growth of HCC cells and overcoming drug resistance for improving the treatment of HCC. Violacein is a deep violet-colored indole derivative that is produced by several bacterial strains, including Chromobacterium violaceum, and it possesses numerous pharmacological properties, including antitumor activity. However, the therapeutic effects of violacein and the mechanism underlying its antitumor effect against HCC remain to be elucidated. This study is the first to demonstrate that violacein inhibits the proliferation and stemness of Huh7 and Hep3B HCC cells. The antiproliferative effect of violacein was attributed to cell cycle arrest at the sub-G1 phase and the induction of apoptotic cell death. Violacein induced nuclear condensation, dissipated mitochondrial membrane potential (MMP), increased generation of reactive oxygen species (ROS), activated the caspase cascade, and upregulated p53 and p21. The anticancer effect of violacein on HCC cells was also associated with the downregulation of protein kinase B (AKT) and extracellular signal-regulated kinase (ERK)1/2 signaling. Violacein not only suppressed the proliferation and formation of tumorspheres of Huh7 and Hep3B cancer stem-like cells but also reduced the expression of key markers of cancer stemness, including CD133, Sox2, Oct4, and Nanog, by inhibiting the signal transducer and activator of transcription 3 (STAT3) / AKT / ERK pathways. These results suggest the therapeutic potential of violacein in effectively suppressing HCC by targeting the proliferation and stemness of HCC cells.
\end{abstract}

Keywords: violacein; hepatocellular carcinoma; proliferation; apoptosis; stemness

\section{Introduction}

Hepatocellular carcinoma (HCC) is a primary malignancy of the liver, and it accounts for approximately 75\% of all cases of liver cancer [1]. In 2018, HCC was the seventh most prevalent cancer worldwide and the second most common cause of cancer-related mortality [2]. In particular, the incidence of HCC is high in Asia and Africa [3]. The primary causes of HCC include chronic hepatitis B virus (HBV) or chronic hepatitis $C$ virus (HCV) infections, alcoholic cirrhosis, and non-alcoholic steatohepatitis (NASH) [4]. To date, the early diagnosis and effective treatment of HCC continues to be a challenge. Most patients are asymptomatic and develop symptoms at an advanced stage of the disease. The long-term prognosis of treatment is good when detected very early; however, for the majority of patients with HCC, the disease is detected at a stage where surgical treatment is no longer feasible [5]. Therefore, most patients with HCC require chemotherapy, which involves the use of chemical agents for destroying cancer cells and inhibiting the growth 
of new cancer cells [6]. Chemotherapy, along with radiation therapy, surgery, and immunotherapy, have been used for the treatment of HCC for many years, but the progress is poor due to the high recurrence rate and frequent cirrhosis [7]. Sorafenib, a tyrosine kinase inhibitor, inhibits the activities of Raf kinase and vascular endothelial growth factor receptor (VEGFR), and it is the most commonly used targeted chemotherapy drug for the treatment of HCC. However, it has been demonstrated that sorafenib improves patient survival by only about $7-10$ months [8,9]. Other kinase inhibitors that have been recently approved for the treatment of HCC include regorafenib and lenvatinib. However, the treatment benefits of these drugs have not been shown to be significantly superior to those of sorafenib $[10,11]$. Therefore, for the effective treatment of HCC, continued studies are necessary for identifying novel candidate drugs to overcome drug resistance.

Apoptosis, a genetically encoded cell death program, is associated with characteristic morphological and biochemical changes, including chromatin condensation, DNA fragmentation, and loss of mitochondrial membrane potential (MMP) [12,13]. Apoptosis is activated by intrinsic and extrinsic pathways and is modulated by a multitude of factors, including intracellular mediators of signal transduction and nuclear proteins that regulate gene expression, DNA replication, and the cell cycle [13]. Representatively, the activation of caspases, the increased expression of tumor suppressor p53, and the generation of reactive oxygen species (ROS) are major factors for the initiation of apoptosis and are molecular targets of numerous anticancer drugs $[14,15]$. As the main goal of cancer therapy is to eliminate cancer cells while minimizing damage to normal cells, the specific apoptosis of cancer cells can serve as a promising therapeutic strategy against cancer [16]. Therefore, drugs that induce the specific apoptosis of HCC cells can be considered as a potential treatment option for the disease.

Cancer stem cells (CSCs), also known as tumor-initiating cells (TICs), have stem celllike properties and are defined as a small subpopulation of cancer cells that contributes to tumor diversity and heterogeneity $[17,18]$. CSCs are more tumorigenic and resistant to anticancer therapies than non-stem cancer cells $[18,19]$. Therefore, CSCs are closely related to tumor carcinogenesis, recurrence, and metastasis $[18,19]$. Mature hepatocytes, hepatoblasts, and bile cells can transform into liver CSCs (LCSCs) during liver injury and trigger hepatic regeneration or lead to a state of oncogenic dedifferentiation [20]. LCSCs are being increasingly recognized as responsible for the initiation, relapse, metastasis, and chemoresistance of HCC [21]. Therefore, the suppression of LCSCs is a promising strategy for the effective treatment of HCC and the prevention of relapse.

Natural products are a highly useful source of bioactive molecules and serve as an important and valuable resource for drug development [22]. Several preclinical and research findings have demonstrated that bioactive compounds derived from natural products show considerable potential in the prevention and treatment of several types of cancer [22,23]. Violacein, an indole derivative produced as a secondary metabolite of Chromobacterium violaceum (Figure 1A), is a purple-colored natural pigment that exhibits various biological properties, including antimicrobial, antiparasitic, anti-inflammatory, and antitumor activities [24]. Previous studies have demonstrated that violacein exhibits anticancer activity by inducing apoptosis in various types of cancer, including breast cancer, colon cancer, lung cancer, and leukemia [25-27]. However, the mechanism underlying the anticancer effect of violacein in HCC remains to be elucidated.

In this study, the anticancer effects and molecular mechanism underlying the anticancer property of violacein in Huh7 and Hep3B HCC cells were investigated. The results of our study demonstrate that violacein effectively inhibited the proliferation of HCC cells by upregulating the apoptotic pathways and also eradicated the stem-like features by downregulating major cancer stemness regulators in HCC cells. We therefore suggest that the natural compound violacein can serve as a potential therapeutic alternative for HCC. 
A<smiles>O=C1NC(c2c[nH]c3ccc(O)cc23)=C/C1=C1/C(=O)Nc2ccccc21</smiles>

D

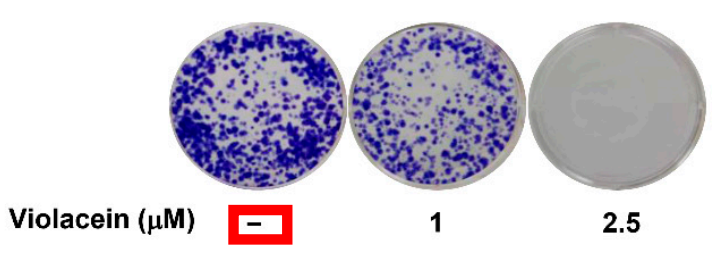

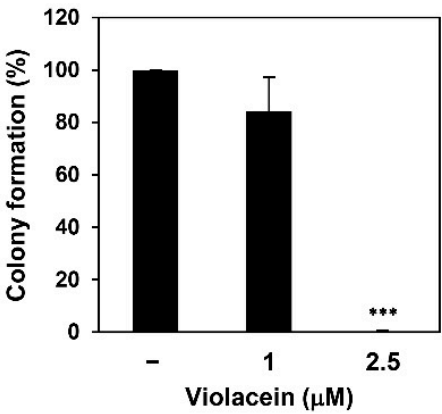

B

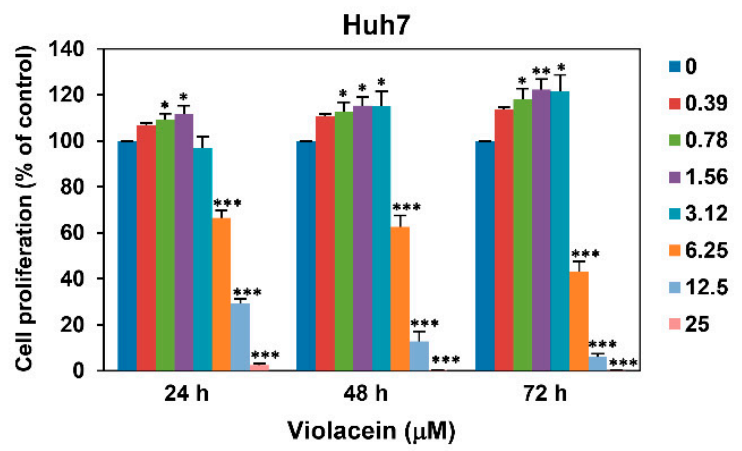

C

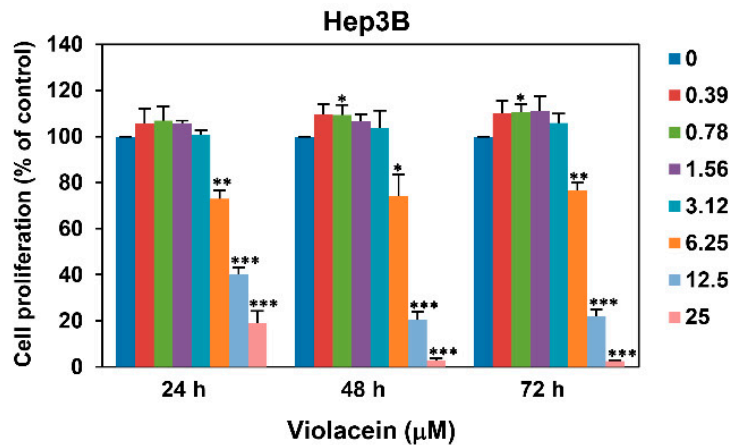

Figure 1. Violacein inhibits the proliferation of Huh7 HCC cells. (A) Chemical structure of violacein. (B,C) Effect of violacein on the proliferation of Huh7 and Hep3B cells. The cells were treated with violacein at various concentrations $(0-25 \mu \mathrm{M})$ for 24, 48, or $72 \mathrm{~h}$. Cell proliferation was measured using the CellTiter-Glo ${ }^{\circledR}$ luminescent assay system. (D) Effect of violacein on the colony-forming ability of Huh7 cells. The cells were incubated in the absence or presence of violacein $(1$ and $2.5 \mu \mathrm{M})$ for 12 days. The cell colonies were detected by crystal violet staining. ${ }^{*} p<0.05,{ }^{* *} p<0.01,{ }^{* * *} p<0.001$ vs. the control.

\section{Results}

\subsection{Violacein Inhibits the Proliferation of Huh7 HCC Cells}

In order to examine whether violacein affects the proliferation of HCC cells, Huh7 cells were treated with violacein at various concentrations $(0-25 \mu \mathrm{M})$ for 24,48 , or $72 \mathrm{~h}$. Cell proliferation was subsequently measured using the ATP-monitoring luminescence assay. As depicted in Figure 1B, treatment with violacein showed a biphasic dose-response on the proliferation of Huh7 cells. At low concentrations $(0.39-3.12 \mu \mathrm{M})$, violacein induced the proliferation of Huh7 cells. However, at higher concentrations (6.25-25 $\mu \mathrm{M})$, it inhibited the Huh7 cell proliferation, with $\mathrm{IC}_{50}$ values of $7.97,6.71$, and $6.10 \mu \mathrm{M}$ at 24,48 , and $72 \mathrm{~h}$, respectively. A similar pattern of dose-response was observed in different HCC cells, Hep3B (Figure $1 \mathrm{C}$ ). The $\mathrm{IC}_{50}$ values of violacein for Hep3B cells were determined to be $8.01,8.41$, and $8.23 \mu \mathrm{M}$ at 24,48 , and $72 \mathrm{~h}$, respectively. These data indicate that violacein may have a biphasic effect on the proliferation of HCC cells by modulating the action of molecular targets involved in HCC cell proliferation in a concentration-dependent biphasic manner.

We next evaluated the effect of violacein on the formation of Huh7 cell colonies. Colony formation was observed on day 12 after treatment with violacein. As depicted in Figures 1D and S1, $2.5 \mu \mathrm{M}$ violacein completely suppressed the colony-forming ability of Huh7 cells. Taken together, these results demonstrate that violacein has inhibitory potential on the proliferation of HCC cells.

\subsection{Violacein Promotes Apoptotic Characteristics in Huh7 HCC Cells}

In order to further investigate the mechanisms underlying the antiproliferative effect of violacein in Huh7 HCC cells, we determined by 4',6-diamidino-2-phenylindole (DAPI) staining whether violacein causes nuclear morphological changes in Huh7 cells. As de- 
picted in Figure 2A, treatment with violacein caused nuclear condensation, a prominent hallmark of apoptosis.

A

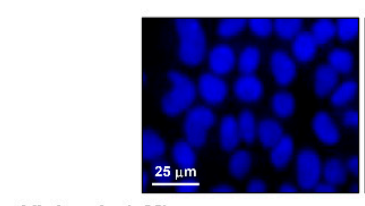

Violacein $(\mu \mathrm{M})$

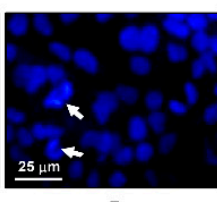

5

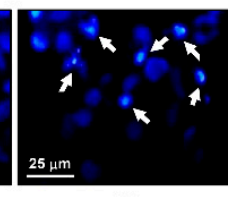

10

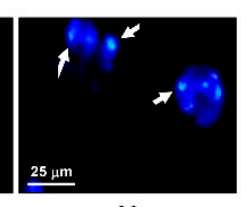

20
B

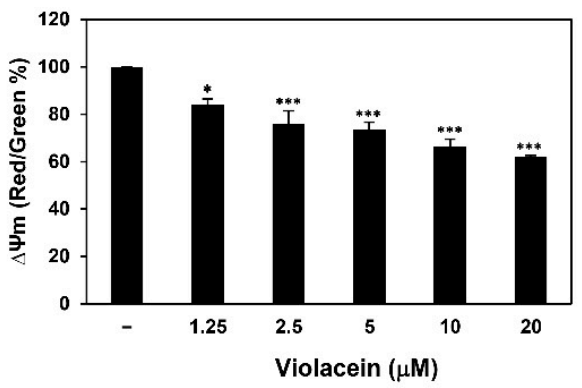

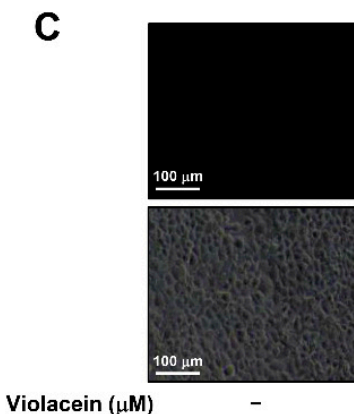
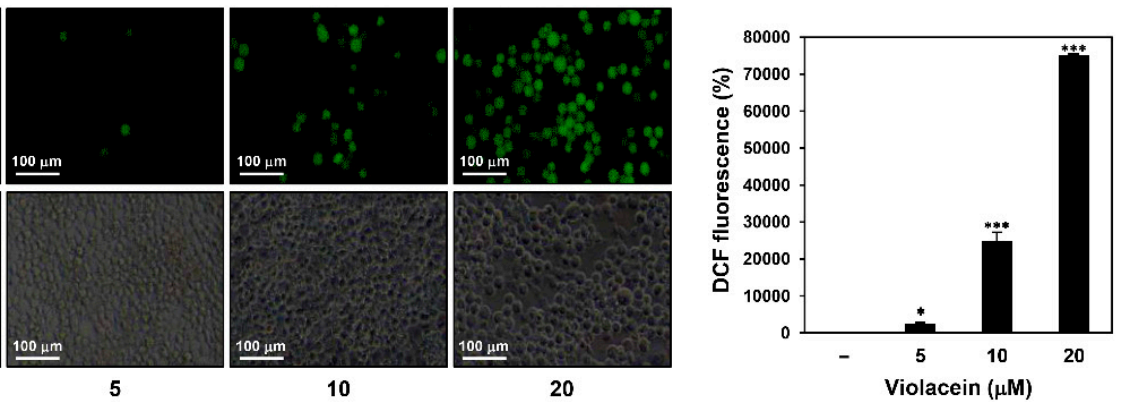

Figure 2. Violacein promotes apoptotic characteristics in Huh7 HCC cells. (A) Effect of violacein on the nuclear morphology. Huh7 cells were treated with violacein $(5,10$, and $20 \mu \mathrm{M})$ for $24 \mathrm{~h}$. Changes in nuclear morphology were monitored by DAPI staining under a fluorescence microscope. The condensed nuclei are indicated by white arrows. (B) Effect of violacein on the MMP. Huh7 cells were treated with violacein $(0-20 \mu \mathrm{M})$ for $24 \mathrm{~h}$ and stained with JC- 1 . The fluorescence intensity of J-aggregates and JC-1 monomers was detected by a multimode microplate reader. (C) Effect of violacein on the generation of intracellular ROS. Huh7 cells were treated with violacein $(5,10$, and $20 \mu \mathrm{M})$ for $6 \mathrm{~h}$. The levels of ROS were detected with DCFH-DA using a fluorescence microscope and were further quantified by densitometry. ${ }^{*} p<0.05,{ }^{* * *} p<0.001$ vs. the control.

The loss of MMP $(\Delta \psi \mathrm{m})$ can induce early apoptosis [12,13]. We therefore evaluated the effect of treatment with violacein on the MMP in Huh7 cells using the cationic 5,5',6,6'tetra-chloro-1,1',3,3'-tetraethylbenzimidazol-carbocyanine iodide (JC-1) fluorescent dye. As depicted in Figure 2B, violacein significantly decreased the ratio of intensity of red/green fluorescence in a dose-dependent manner, indicating that violacein caused the loss of MMP in Huh7 cells.

Intracellular ROS play a central role in biological processes, especially in the induction of apoptosis $[12,15]$. In order to assess whether violacein affects the generation of ROS in Huh7 cells, the level of intracellular ROS was measured using $2^{\prime}, 7^{\prime}$-dichlorofluorescein diacetate (DCFH-DA). Violacein significantly increased the accumulation of ROS in a dosedependent manner (Figure 2C). Taken together, these results suggest that violacein may inhibit the proliferation of Huh7 HCC cells by inducing apoptotic cell death.

\subsection{Violacein Induces Cell Cycle Arrest at the Sub-G1 Phase and Cellular Apoptosis in Huh7 HCC Cells}

In order to further explore the role of apoptosis in the inhibitory effect of violacein on the proliferation of HCC cells, we investigated the effect of violacein on the progression of the cell cycle in Huh7 cells by flow cytometric analysis. DNA fragmentation can be measured by flow cytometry using the sub-G1 assay. The small DNA fragments generated during apoptosis leak out of cells, decreasing the total DNA content of apoptotic cells. By staining DNA with PI, hypodiploid apoptotic cells can be detected as a "sub-G1" population of the PI histogram. As depicted in Figure 3A, treatment with violacein significantly 
increased the population of cells in the sub-G1 phase and decreased the population of cells in the G0/G1, S, and G2/M phases, compared with those of the untreated control group. These data imply that violacein caused nuclear fragmentation in the HCC cells and consequently arrested cell cycle progression at the sub-G1 phase, which represents apoptotic cells.
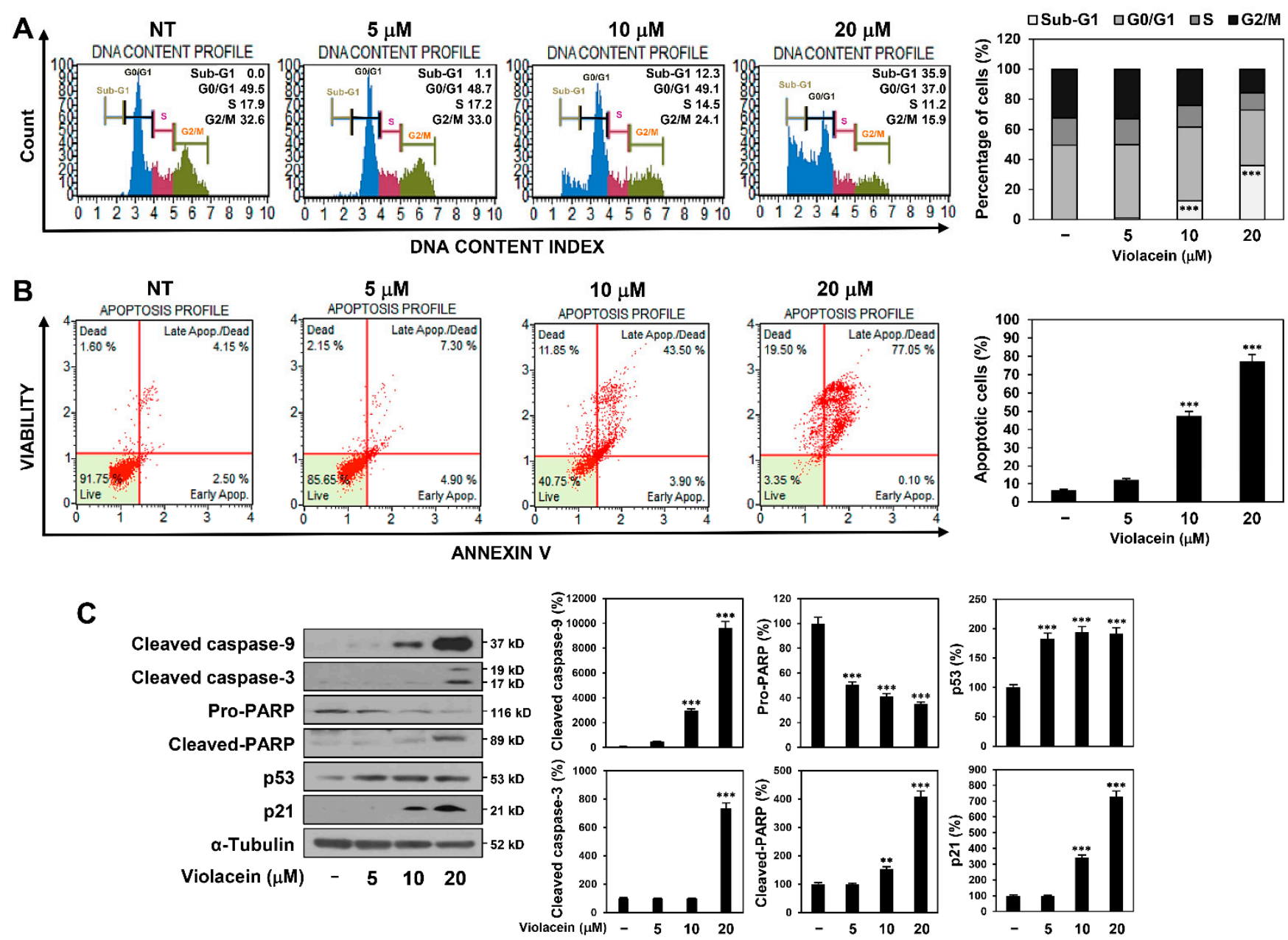

Figure 3. Violacein induces cell cycle arrest at the sub-G1 phase and cellular apoptosis in Huh7 HCC cells. (A-C) Huh7 cells were treated with violacein $(5,10$, and $20 \mu \mathrm{M})$ for $24 \mathrm{~h}$. (A) Effect of violacein on the cell cycle. The cell cycle distribution was evaluated using a Muse Cell Analyzer with Muse ${ }^{\circledR}$ Cell Cycle kit. (B) Effect of violacein on the apoptotic cell death. Apoptotic cells were detected using a Muse Cell Analyzer with Muse ${ }^{\circledR}$ Annexin V \& Dead Cell kit. (C) Effect of violacein on the expression of apoptosis regulators. Protein levels were detected by Western blot analysis using specific antibodies and were further quantified by densitometry. $\alpha$-tubulin levels were used as an internal control. ${ }^{* *} p<0.01,{ }^{* * *} p<0.001$ vs. the control.

Next, cellular apoptosis was analyzed by flow cytometry by Annexin V-FITC and PI dual labeling. Treatment with violacein significantly increased the proportion of apoptotic cells in a dose-dependent manner compared with that in the untreated control group (Figure 3B). These data demonstrate that violacein induced apoptosis in Huh7 HCC cells.

In order to further elucidate the molecular mechanism underlying violacein-induced apoptosis, we assessed the effect of violacein on the expression of crucial mediators of apoptosis in Huh7 cells. Caspases play an important role in apoptosis and are activated by proteolytic cleavage $[12,13]$. Upon induction of apoptosis, cytochrome c released from mitochondria associates with caspase- 9 and apoptotic protease activating factor-1 (Apaf-1). The complex processes caspase-9 $(47 \mathrm{kD})$ into several subunits, including a p37 fragment $(37 \mathrm{kD})$. The cleaved caspase- 9 further processes caspase-3 $(35 \mathrm{kD})$ that is a critical 
executioner of apoptosis. The cleaved caspase-3 (17/19 kD) is responsible for the proteolytic cleavage $(89 \mathrm{kD})$ of downstream substrates involved in apoptotic changes, including a 116 kD nuclear poly (ADP-ribose) polymerase (PARP). As depicted in Figure 3C, treatment with violacein increased the levels of cleaved caspase-9, cleaved caspase-3, and cleaved PARP. Additionally, violacein upregulated the expression of the tumor suppressor $\mathrm{p} 53$ and its transcriptional target, p21, which are implicated in both cell cycle arrest and apoptosis. These results suggest that violacein may induce cellular apoptosis via the activation of p53and caspase-mediated apoptotic pathways in Huh7 HCC cells.

\subsection{Violacein Downregulates Protein Kinase B (AKT) and Extracellular Signal-Regulated Kinase (ERK) Signaling in Huh7 HCC Cells}

Aberrantly activated AKT and ERK signaling contributes to the survival and proliferation of several types of cancers, including HCC [28]. AKT is a serine/threonine kinase that promotes cell survival by inhibiting apoptosis. ERK1 and ERK2 isoforms are 44 and $42 \mathrm{kD}$ serine/threonine kinases, respectively, belonging to the mitogen-activated protein kinase family. We therefore examined whether violacein affects the key signaling pathways in Huh7 cells. In particular, to clarify whether the inhibitory effect of violacein on HCC cell proliferation is due to inactivation of the signaling pathways, the effect of the compound was evaluated at the early time point of $1 \mathrm{~h}$. As depicted in Figure 4, violacein more effectively inhibited the expression levels of phosphorylated forms compared with unphosphorylated AKT and ERK1/2 proteins. These data indicate that the antiproliferative effect of violacein on Huh7 cells could be mediated via the downregulation of AKT and ERK signaling pathways.
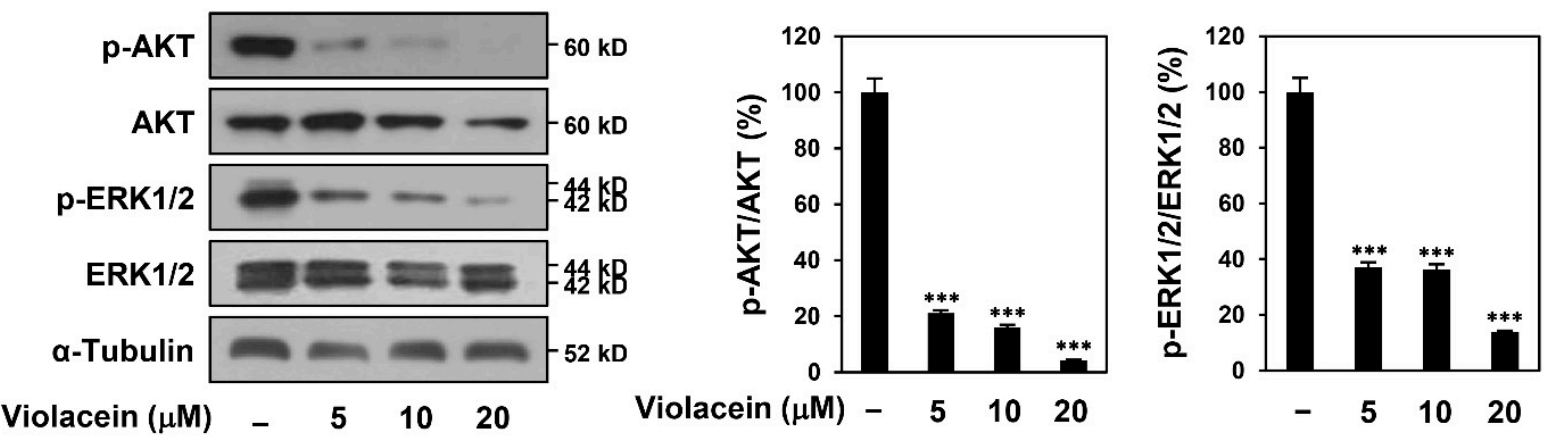

Figure 4. Violacein downregulates AKT and ERK signaling in Huh7 HCC cells. The cells were treated with violacein $(5,10$, and $20 \mu \mathrm{M})$ for $1 \mathrm{~h}$. Protein levels were detected by Western blot analysis using specific antibodies and were further quantified by densitometry. $\alpha$-tubulin levels were used as an internal control. ${ }^{* * *} p<0.001$ vs. the control.

\subsection{Violacein Inhibits the Proliferation and Formation of Tumorspheres of Huh7 Cancer Stem-Like Cells}

Accumulating evidence has revealed that CSCs, a subpopulation of tumor cells, facilitate metastasis, recurrence, and resistance to chemotherapy or radiotherapy in HCC [17]. We therefore further investigated the effect of violacein on the stemness of Huh7 cells. In order to propagate the cancer stem-like cells, Huh7 cells were grown in serum-free spheroid suspension culture [29]. The 3D spheroid cell culture is known to stimulate in vivo cellular conditions better in comparison with 2D cell culture, and it is widely used to increase a subpopulation of cancer cells with stem cell-like properties, thereby providing new insights into cancer treatment and CSC research [29]. As depicted in Figure S2, the expression levels of several key stemness-related markers were remarkably increased in the Huh7 tumorsphere cells cultured in serum-free media containing EGF and bFGF compared to the Huh7 adherent cells cultured in 10\% FBS-supplemented media. These data indicate that the serum-free spheroid culture can expand the CSC population from HCC cell lines.

The Huh7 cancer stem-like cells were treated with violacein at various concentrations $(0-100 \mu \mathrm{M})$ for 7 days, and cell proliferation was measured using the ATP-monitoring 
luminescence assay. As depicted in Figure 5A, treatment with violacein inhibited the proliferation of Huh7 cancer stem-like cells, and the $\mathrm{IC}_{50}$ value was determined to be 16.47 $\mu \mathrm{M}$. Furthermore, both the size and number of tumorspheres formed by the Huh7 cancer stem-like cells were effectively reduced following treatment with violacein (Figure 5B,C). In particular, the tumorsphere-forming ability was remarkably suppressed by violacein, even at concentrations 10 times lower than the $\mathrm{IC}_{50}$ value for inhibiting the proliferation of Huh7 cancer stem-like cells. We further identified that violacein potently inhibited the tumorsphere-forming ability of Hep3B cancer stem-like cells (Figure S3). These data suggest the possible therapeutic potential of violacein in eradicating CSCs in HCC.

A

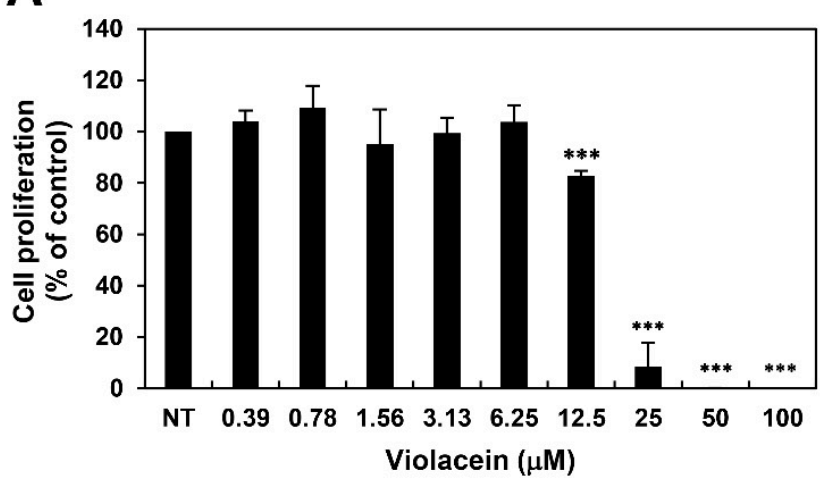

C
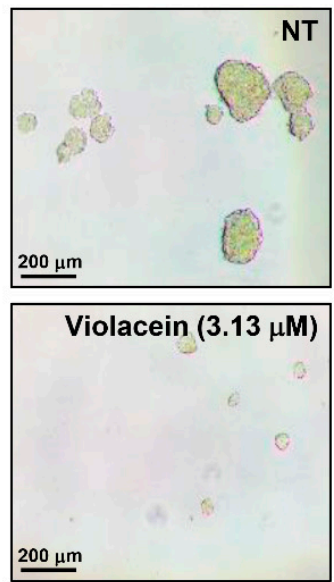
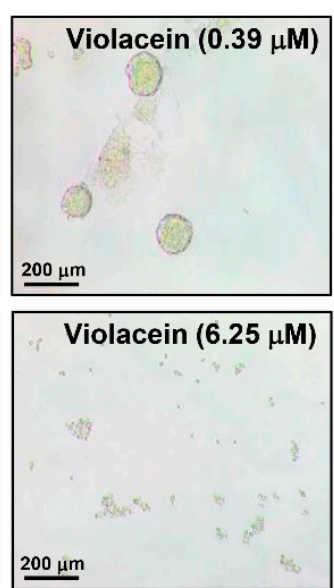

$200 \mu \mathrm{m}$
B
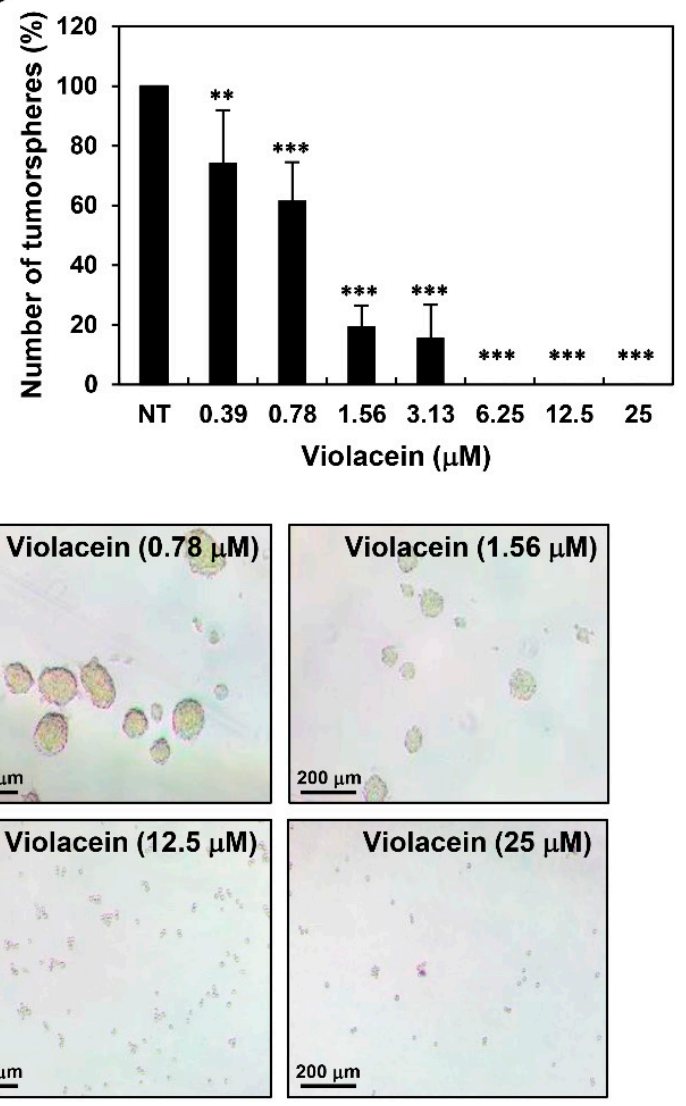
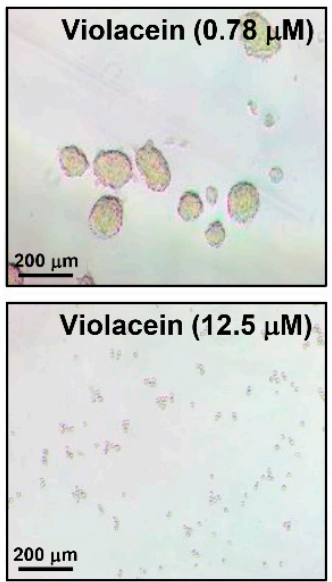

Figure 5. Violacein inhibits the proliferation and formation of tumorspheres of Huh7 cancer stem-like cells. (A) Effect of violacein on the proliferation of Huh7 cancer stem-like cells. The cells were treated with violacein at various concentrations $(0-100 \mu \mathrm{M})$ and were incubated with the CSC culture media for 7 days. Cell proliferation was measured using the CellTiterGlo ${ }^{\circledR}$ luminescent assay system. (B,C) Effect of violacein on the tumorsphere-forming ability of Huh7 cancer stem-like cells. The cells were treated with violacein at various concentrations $(0-25 \mu \mathrm{M})$ and were incubated with the CSC culture media for 7 days. The number of tumorspheres in each well was counted under an optical microscope. ${ }^{* *} p<0.01,{ }^{* * *} p<0.001$ vs. the control.

2.6. Violacein Downregulates Cancer Stemness-Related Markers and Signal Transducer and Activator of Transcription 3 (STAT3)/AKT/ERK Signaling in Huh7 Cancer Stem-Like Cells

We next evaluated whether violacein regulates the expression of key stemness-related markers in the CSCs in HCC. The results demonstrate that violacein markedly suppressed the expression of CD133, Sox2, Oct4, and Nanog in Huh7 cancer stem-like cells (Figure 6A). However, it slightly inhibited the expression of aldehyde dehydrogenase 1A1 (ALDH1A1) at concentrations of 1 and $5 \mu \mathrm{M}$, while it did not reduce the protein levels at $2.5 \mu \mathrm{M}$. Meanwhile, violacein suppressed the expression of integrin $\alpha 6$ (125 kD reduced and 150 $\mathrm{kD}$ nonreduced forms) at 1 and $2.5 \mu \mathrm{M}$ treatment, but not at $5 \mu \mathrm{M}$. 
A

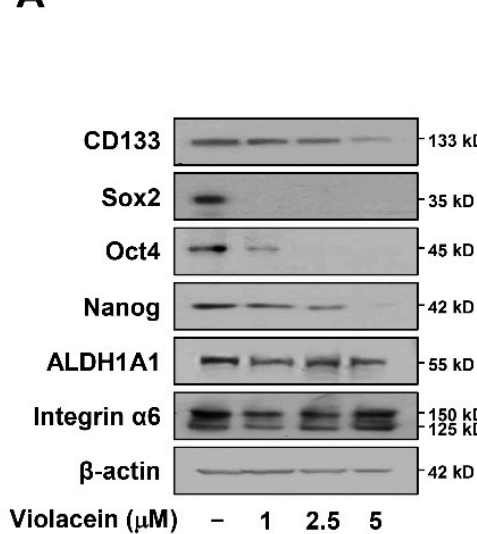

Violacein ( $\mu$ M) -12.55
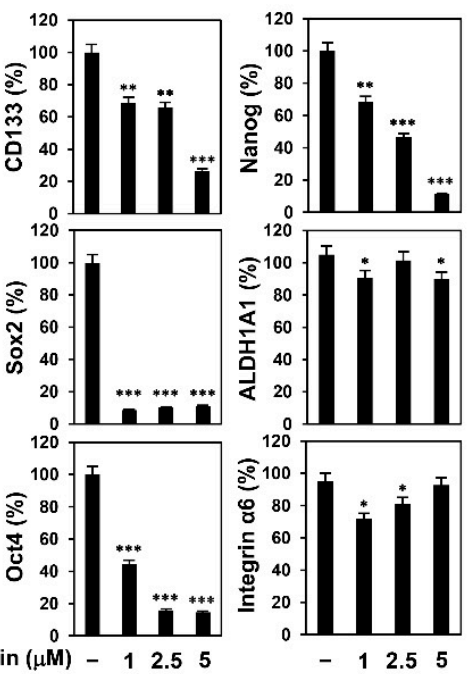

B

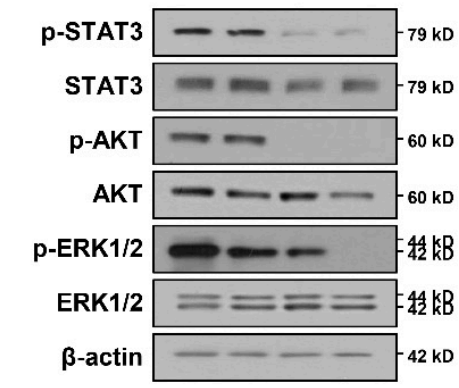

Violacein $(\mu \mathrm{M}) \quad-\quad 12.5 \quad 5$

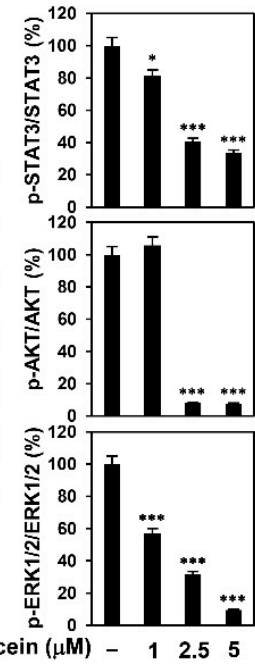

Figure 6. Violacein downregulates cancer stemness-related markers and STAT3/AKT/ERK signaling in Huh7 cancer stem-like cells. (A,B) The cells were treated with violacein $(1,2.5$, and $5 \mu \mathrm{M})$ and were incubated with the CSC culture media for $72 \mathrm{~h}$. Protein levels were detected by Western blot analysis using specific antibodies and were further quantified by densitometry. $\beta$-actin levels were used as an internal control. ${ }^{*} p<0.05,{ }^{* *} p<0.01,{ }^{* * *} p<0.001$ vs. the control.

It has been reported that STAT3 signaling regulates the expression of several CSC markers, including CD133 and Nanog, in HCC [30]. The AKT and ERK signaling pathways are also involved in the maintenance of self-renewal in CSCs in HCC [31,32]. Treatment with violacein inhibited the phosphorylation of STAT3, AKT, and ERK1/2 without affecting the total protein expression (Figure 6B). These results demonstrate that violacein may inhibit the stem-like features of Huh7 HCC cells by inactivating the STAT3/AKT/ERK pathway.

\section{Discussion}

HCC is the most common primary malignancy of the liver, with a high mortality rate that is attributed to difficulties in early diagnosis, high recurrence rate, and frequent cirrhosis $[1,7]$. Therefore, the continued exploration and development of novel anticancer agents is necessary for reducing the rate of recurrence of HCC and achieving effective chemotherapy.

Violacein is a natural pigment with numerous biological activities, and it is obtained from several bacterial strains, including C. violaceum [24]. Several studies have demonstrated that violacein can induce apoptosis in a variety of cancer cells, including breast cancer, colon cancer, lung cancer, and leukemia [25-27]. It has been demonstrated that violacein induces the accumulation of ROS in tumors by increasing the expression of genes related to oxidative stress, including GSK $3 \beta$ and TNF- $\alpha$, and induces apoptosis by upregulating the expression of apoptosis-inducing genes, including p53, caspase-3, caspase- 8 , caspase-9, and PARP $[25,26]$. However, the anticancer activity and mechanism underlying the antitumor effect of violacein in HCC are yet to be investigated. This study was the first to evaluate the anticancer effect of violacein in Huh7 and Hep3B HCC cells.

The evasion of apoptosis is the hallmark of cancer and results in cancer progression and drug resistance [33]. Therefore, the induction of apoptosis through the reactivation of major apoptotic pathways and the inhibition of cell survival signaling cascades can offer a potential strategy for efficiently suppressing the growth of HCC cells. The results of our study demonstrate that violacein effectively inhibited the proliferation of HCC cells by inducing apoptosis. Violacein causes cell cycle arrest at the sub-G1 phase and activates the key regulatory mechanisms of apoptosis, including nuclear condensation, dissipation of MMP, increased generation of ROS, activation of the caspase cascade, and upregulation of p53 and p21. Additionally, the antiproliferative effect of violacein on HCC cells was mediated via the downregulation of AKT and ERK1/2 signaling pathways, which play an 
important role in sustaining proliferation and preventing the apoptosis of tumor cells [28]. These findings demonstrate that violacein potently inhibits the proliferation of HCC cells via activation of apoptotic pathways and deactivation of survival pathways.

CSCs are a small subpopulation of cancer cells with stem cell properties, including self-renewal and multilineage differentiation, and they have been identified in many tumors, including liver cancer [17-19]. It has been demonstrated that LCSCs, also known as hepatic cancer stem cells, contribute to the initiation, relapse, metastasis, and chemoresistance of HCC [20,21]. Therefore, LCSCs are a vital target for the successful treatment of HCC. Notably, the results of our study demonstrate that violacein significantly inhibited the proliferation and formation of tumorspheres of Huh7 and Hep3B cancer stem-like cells. Additionally, violacein effectively suppressed the key stemness-related markers and signaling pathways in cells.

Accumulating evidence has revealed that several cell surface markers, transcription factors, and molecular signaling pathways are activated in LCSCs, which mediate the development and maintenance of LCSCs [34,35]. The CD133 cell surface marker has been detected in numerous types of CSCs, and CD133-positive HCC has stronger carcinogenicity and proliferative capacity [34]. The key regulatory transcription factors, including Sox2, Oct4, and Nanog, not only play a critical role in the maintenance and self-renewal of LCSCs but also contribute to the malignancy of HCC via mechanisms related to drug resistance, including epithelial-mesenchymal transition (EMT) [21,34-36]. ALDH1A1, an isoform of the aldehyde dehydrogenase enzyme, partakes in the clearance of toxic aldehydes and reduces oxidative stress, which consequently leads to the survival of CSCs and poor prognosis [37]. Integrin $\alpha 6$, the receptor for the extracellular matrix (ECM) protein laminin, plays an important role in maintaining the CSC niche and regulating homeostasis in CSCs [36]. In this study, violacein noticeably reduced the expression levels of CD133, Sox2, Oct4, and Nanog in Huh7 cancer stem-like cells. However, it differently regulated the expression levels of ALDH1A1 and integrin $\alpha 6$ at each treatment concentration.

Additionally, several molecular signaling pathways, including the STAT3, AKT, and ERK pathways, are aberrantly activated in HCC, leading to the dysregulation of downstream target genes that control proliferation, survival, invasion, and stemness [30-32]. Activated STAT3 translocates to the nucleus and induces the transcription of several markers of CSCs in HCC, including CD133 and Nanog, thereby promoting the maintenance and self-renewal of LCSCs $[38,39]$. The AKT and ERK signaling pathways are also implicated in the proliferation, metabolism, and differentiation of LCSCs via upregulation of the expression of Sox2, Oct4, and Nanog [31,32,40]. The results of our study demonstrate that violacein significantly inhibited the phosphorylation of STAT3, AKT, and ERK1/2 without reducing the total protein levels in Huh7 cancer stem-like cells. These findings suggest that violacein may suppress the cancer stem-like features of HCC cells by inhibiting the expression of key cancer stemness markers, including CD133, Sox2, Oct4, and Nanog, via downregulation of the STAT3/AKT/ERK signaling pathways.

Taken together, the study demonstrates the therapeutic potential of violacein in effectively suppressing HCC by targeting both the proliferation and stemness of HCC cells. However, further in vivo experiments with animal models and identification of the primary molecular target of violacein are necessary before violacein can be used for the clinical treatment of HCC.

\section{Materials and Methods}

\subsection{Materials}

Violacein was kindly provided by Prof. Jae Kyung Sohng (Sun Moon University, Asan, Korea) and dissolved in dimethyl sulfoxide (DMSO) at a concentration of $100 \mathrm{mM}$. Dulbecco's modified Eagle's medium (DMEM) and Roswell Park Memorial institute-1640 (RPMI-1640) were purchased from Corning Cellgro (Manassas, VA, USA). DMEM/F12 and trypsin were purchased from HyClone (Marlborough, MA, USA). Epidermal growth factor (EGF) and basic fibroblast growth factor (bFGF) were obtained from Prospecbio (East 
Brunswick, NJ, USA). Fetal bovine serum (FBS), B-27 serum-free supplement, L-glutamine, and penicillin/streptomycin were obtained from Gibco (Grand Island, NY, USA). Penicillinstreptomycin-amphotericin B and Accutase were obtained from Lonza (Walkersville, MD, USA) and EMD Millipore (Temecula, CA, USA), respectively. Heparin, DAPI, DCFH-DA, and JC-1 were purchased from Sigma-Aldrich (St. Louis, MO, USA). The CellTiter-Glo ${ }^{\circledR}$ 2.0 Cell Viability Assay kit was purchased from Promega (Madison, WI, USA). The Muse ${ }^{\circledR}$ Annexin V \& Dead Cell and Muse ${ }^{\circledR}$ Cell Cycle kits were purchased from Luminex (Austin, TX, USA). The antibodies against cleaved caspase-9 (cat. no. 9501), cleaved caspase-3 (cat. no. 9661), PARP (cat. no. 9542), p53 (cat. no. 2524), p21 (cat. no. 2947), ALDH1A1 (cat. no. 12035), Integrin $\alpha 6$ (cat. no. 3750), Sox2 (cat. no. 3579), Oct4 (cat. no. 2750), Nanog (cat. no. 3580), CD133 (cat. no. 64326), phospho-STAT3 (cat. no. 9145), STAT3 (cat. no. 9139), phospho-AKT (cat. no. 4060), AKT (cat. no. 9272), phospho-ERK1/2 (cat. no. 9101), ERK1/2 (cat. no. 9102), $\alpha$-tubulin (cat. no. 2144), rabbit IgG (cat. no. 7074), and mouse IgG (cat. no. 7076) were purchased from Cell Signaling Technology (Danvers, MA, USA). Anti- $\beta$-actin antibody (cat. no. ab6276) was purchased from Abcam (Cambridge, UK).

\subsection{Cell Culture}

Huh7 and Hep3B human HCC cells were purchased from the Korean Cell Line Bank (Seoul, Korea). The Huh7 and Hep3B cells were grown in DMEM supplemented with 10\% FBS and 1\% penicillin-streptomycin-amphotericin B, respectively. The Huh7 and Hep3B cancer stem-like cells were cultured in DMEM/F12 containing $1 \times \mathrm{B}-27,5 \mu \mathrm{g} / \mathrm{mL}$ heparin, $2 \mathrm{mM}$ L-glutamine, $20 \mathrm{ng} / \mathrm{mL}$ EGF, $20 \mathrm{ng} / \mathrm{mL}$ bFGF, and $1 \%$ penicillin/streptomycin. All the cells were maintained at $37^{\circ} \mathrm{C}$ in a humidified $\mathrm{CO}_{2}$ incubator with $5 \% \mathrm{CO}_{2}$ (Thermo Scientific, Vantaa, Finland).

\subsection{Cell Proliferation Assay}

Cell proliferation was quantitatively evaluated using the CellTiter-Glo ${ }^{\circledR} 2.0$ Cell Viability Assay kit. Briefly, the cells $\left(5 \times 10^{3}\right.$ cells /well) were seeded in a 96-white-well culture plate and treated with violacein at various concentrations. Following incubation for the indicated durations, $20 \mu \mathrm{L}$ of substrate solution was added to each well, and the culture plate was shaken for $2 \mathrm{~min}$ and subsequently incubated for $8 \mathrm{~min}$ in the dark. Luminescence was detected using a multimode microplate reader (BioTek, Inc., Winooski, VT, USA). The $\mathrm{IC}_{50}$ values determined from the obtained data were analyzed by the curve-fitting program in GraphPad Prism, version 5 (GraphPad Software, La Jolla, CA, USA).

\subsection{Colony Formation Assay}

Huh7 cells $\left(1 \times 10^{3}\right.$ cells/well) were seeded in 6-well culture plates and treated with violacein. After 12 days of incubation, the colonies that had formed were fixed with $3.7 \%$ formaldehyde by incubating for $20 \mathrm{~min}$, and stained with $0.5 \%$ crystal violet reagent by incubating for $15 \mathrm{~min}$. The stained colonies were washed with phosphate-buffered saline (PBS), and the number of visible colonies in each well was counted.

\subsection{Nuclear Fluorescent Staining with DAPI}

Huh7 cells $\left(7 \times 10^{4}\right.$ cells/well $)$ were seeded in 24 -well culture plates and treated with violacein for $24 \mathrm{~h}$. The cells were fixed with $3.7 \%$ formaldehyde by incubating for $15 \mathrm{~min}$ and stained with $5 \mu \mathrm{g} / \mathrm{mL}$ DAPI by incubating for $15 \mathrm{~min}$. The fluorescent images were obtained using a fluorescence microscope (Optinity KI-2000F, Korea Lab Tech, Seong Nam, Korea).

\subsection{Measurement of MMP}

Huh7 cells $\left(5 \times 10^{4}\right.$ cells / well) were seeded in 96-black-well culture plates and treated with violacein for $24 \mathrm{~h}$. The cells were subsequently treated with $10 \mu \mathrm{g} / \mathrm{mL}$ of the JC1 fluorescent dye and were incubated for $20 \mathrm{~min}$. The fluorescence intensity of the Jaggregates that formed and the JC- 1 monomers was detected at wavelengths of 530/590 
$\mathrm{nm}$ (excitation/emission) and 485/528 nm, respectively, using a multimode microplate reader (BioTek, Winooski, VT, USA). Mitochondrial depolarization was indicated by a decrease in the ratio of intensity of red/green fluorescence.

\subsection{Measurement of ROS}

Huh7 cells $\left(5 \times 10^{4}\right.$ cells /well) were seeded in a 24-well culture plate and treated with violacein for $6 \mathrm{~h}$. The cells were stained with $15 \mu \mathrm{M}$ DCFH-DA by incubating for $10 \mathrm{~min}$. The fluorescent images were obtained using a fluorescence microscope (Optinity KI-2000F, Korea Lab Tech, Seong Nam, Korea), and the fluorescence density was analyzed using ImageJ software, version $1.5(\mathrm{NIH})$.

\subsection{Analysis of Apoptosis}

Huh7 cells $\left(2 \times 10^{5}\right.$ cells/well) were seeded in a $60 \mathrm{~mm}$ cell culture dish and treated with violacein for $24 \mathrm{~h}$. The cells were harvested, washed with PBS, and stained with $100 \mu \mathrm{L}$ of Muse ${ }^{\circledR}$ Annexin V \& Dead Cell reagent, according to the manufacturer's instructions. The stained cells were analyzed using a Guava ${ }^{\circledR}$ Muse ${ }^{\circledR}$ Cell Analyzer (MuseSoft_V1.8.0.3; Luminex Corporation, Austin, TX, USA).

\subsection{Cell Cycle Analysis}

Huh7 cells $\left(1 \times 10^{5}\right.$ cells/well $)$ were seeded in a $60 \mathrm{~mm}$ cell culture dish and treated with violacein for $24 \mathrm{~h}$. The cells were harvested, washed with PBS, and fixed with 70\% ethanol at $-20^{\circ} \mathrm{C}$ for $3 \mathrm{~h}$. After washing with PBS, the cells were stained with $200 \mu \mathrm{L}$ of Muse ${ }^{\circledR}$ Cell Cycle reagent, according to the manufacturer's instructions. The stained cells were analyzed using a Guava ${ }^{\circledR}$ Muse ${ }^{\circledR}$ Cell Analyzer.

\subsection{Western Blot Analysis}

The cells were lysed using RIPA buffer, supplemented with protease and phosphatase inhibitors (ATTO, Tokyo, Japan). The concentrations of the proteins were determined using the Pierce ${ }^{\circledR}$ BCA Protein Assay Kit (Thermo Fisher Scientific, Inc., Rockford, IL, USA). Equal amounts of cell lysates were separated by $7.5-15 \%$ sodium dodecyl sulfate-polyacrylamide gel electrophoresis (SDS-PAGE) and subsequently transferred to polyvinylidene difluoride (PVDF) membranes (EMD Millipore, Hayward, CA, USA) using standard electroblotting procedures. The blots were blocked with $5 \%$ skim milk in Tris-buffered saline with Tween-20 (TBST) at room temperature for $1 \mathrm{~h}$, and immunolabeled with the primary antibodies against cleaved capase-9, cleaved caspase-3, PARP, p21, p53, phospho-ERK1/2, ERK1/2, phospho-AKT, AKT, phospho-STAT3, STAT3, ALDH1A1, integrin $\alpha 6$, Sox2, Oct4, Nanog, CD133, $\alpha$-tubulin (dilution 1:2000), and $\beta$-actin (dilution 1:10000) by incubating overnight at $4{ }^{\circ} \mathrm{C}$. After washing thrice with TBST, the membranes were incubated with horseradish peroxidase-conjugated anti-rabbit or anti-mouse (dilution 1:3000) secondary antibody for $1 \mathrm{~h}$ at room temperature. Immunolabeling was detected using an enhanced chemiluminescence (ECL) kit (Bio-Rad Laboratories, Hercules, CA, USA), according to the manufacturer's instructions. The density of the bands was analyzed using ImageJ software, version $1.5(\mathrm{NIH})$.

\subsection{Tumorsphere Forming Assay}

Huh7 and Hep3B cancer stem-like cells $\left(3 \times 10^{3}\right.$ cells/well) were seeded in 96-well culture plates using serum-free media with EGF and bFGF, and they were treated with violacein at various concentrations. After 7 days of incubation, the size and number of tumorspheres were determined using an optical microscope (Olympus, Tokyo, Japan).

\subsection{Statistical Analyses}

The results are presented as the mean \pm standard deviation (SD) of data obtained from at least three independent experiments. The differences among the groups were analyzed by analysis of variance (ANOVA), calculated using the SPSS software, version 9.0 (SPSS 
Inc., Chicago, Ill., USA). Post hoc analysis was performed using Tukey's test. Statistical significance was considered at $p<0.05$.

\section{Conclusions}

This study is the first to demonstrate the anticancer effect of violacein against HCC cells and elucidate the molecular mechanism underlying its antitumor activity. The results demonstrate that violacein effectively inhibited the proliferation of HCC cells by inducing cell cycle arrest at the sub-G1 phase and triggering apoptosis. The apoptosis induced by violacein was associated with nuclear condensation; loss of MMP; increased generation of ROS; activation of caspase-9, caspase-3, and PARP; upregulation of p53 and p21; and downregulation of AKT and ERK1/2 signaling. Furthermore, violacein significantly suppressed the proliferation and formation of tumorspheres of HCC stem-like cells by reducing the expression of HCC stemness markers, including CD133, Sox2, Oct4, and Nanog, and by inhibiting the STAT3/AKT/ERK signaling pathways. In conclusion, these findings suggest that violacein has the chemotherapeutic potential to effectively suppress HCC by targeting both the proliferation and stemness of HCC cells.

Supplementary Materials: The following are available online at https://www.mdpi.com/article/10 .3390/ijms221910731/s1.

Author Contributions: Conceptualization, H.J.J.; methodology, Y.J.K. and N.Y.; software, H.J.J.; validation, Y.J.K.; formal analysis, Y.J.K. and N.Y.; investigation, Y.J.K., N.Y. and H.J.S.; resources, H.J.J.; data curation, Y.J.K. and N.Y.; writing—original draft preparation, Y.J.K.; writing—review and editing, H.J.J.; visualization, Y.J.K., N.Y. and H.J.S.; supervision, H.J.J; project administration, H.J.J.; funding acquisition, H.J.J. All authors have read and agreed to the published version of the manuscript.

Funding: This research was supported by the Basic Science Research Program through the National Research Foundation of Korea funded by the Ministry of Science and ICT (NRF-2019R1A2C1009033) and the Ministry of Education (NRF-2021R111A3050093). This work was also supported by the Brain Korea 21 Project, Republic of Korea.

Institutional Review Board Statement: Not applicable.

Informed Consent Statement: Not applicable.

Data Availability Statement: The data that support the findings of this study are available from the corresponding author upon reasonable request.

Acknowledgments: We are very grateful to Jae Kyung Sohng (Sun Moon University, Asan, Korea) for providing violacein.

Conflicts of Interest: The authors declare no conflict of interest.

\section{References}

1. Altekruse, S.F.; Devesa, S.S.; Dickie, L.A.; McGlynn, K.A.; Kleiner, D.E. Histological classification of liver and intrahepatic bile duct cancers in SEER registries. J. Regist. Manag. 2011, 38, 201-205.

2. Bray, F.; Ferlay, J.; Soerjomataram, I.; Siegel, R.L.; Torre, L.A.; Jemal, A. Global cancer statistics 2018: GLOBOCAN estimates of incidence and mortality worldwide for 36 cancers in 185 countries. CA Cancer J. Clin. 2018, 68, 394-424. [CrossRef]

3. Petrick, J.L.; Florio, A.A.; Znaor, A.; Ruggieri, D.; Laversanne, M.; Alvarez, C.S.; Ferlay, J.; Valery, P.C.; Bray, F.; McGlynn, K.A. International trends in hepatocellular carcinoma incidence, 1978-2012. Int. J. Cancer 2020, 147, 317-330. [CrossRef]

4. Medavaram, S.; Zhang, Y. Emerging therapies in advanced hepatocellular carcinoma. Exp. Hematol. Oncol. 2018, 7, 17. [CrossRef] [PubMed]

5. Dimitroulis, D.; Damaskos, C.; Valsami, S.; Davakis, S.; Garmpis, N.; Spartalis, E.; Athanasiou, A.; Moris, D.; Sakellariou, S.; Kykalos, S.; et al. From diagnosis to treatment of hepatocellular carcinoma: An epidemic problem for both developed and developing world. World J. Gastroenterol. 2017, 23, 5282-5294. [CrossRef] [PubMed]

6. Ogunwobi, O.O.; Harricharran, T.; Huaman, J.; Galuza, A.; Odumuwagun, O.; Tan, Y.; Ma, G.X.; Nguyen, M.T. Mechanisms of hepatocellular carcinoma progression. World J. Gastroenterol. 2019, 25, 2279-2293. [CrossRef] [PubMed]

7. Liu, C.Y.; Chen, K.F.; Chen, P.J. Treatment of liver cancer. Cold Spring Harb. Perspect. Med. 2015, 5, a021535. [CrossRef]

8. Ikeda, M.; Morizane, C.; Ueno, M.; Okusaka, T.; Ishii, H.; Furuse, J. Chemotherapy for hepatocellular carcinoma: Current status and future perspectives. Jpn. J. Clin. Oncol. 2018, 48, 103-114. [CrossRef] 
9. Keating, G.M. Sorafenib: A review in hepatocellular carcinoma. Target. Oncol. 2017, 12, 243-253. [CrossRef]

10. Personeni, N.; Pressiani, T.; Santoro, A.; Rimassa, L. Regorafenib in hepatocellular carcinoma: Latest evidence and clinical implications. Drugs Context 2018, 7, 212533. [CrossRef]

11. Spallanzani, A.; Orsi, G.; Andrikou, K.; Gelsomino, F.; Rimini, M.; Riggi, L.; Cascinu, S. Lenvatinib as a therapy for unresectable hepatocellular carcinoma. Expert Rev. Anticancer Ther. 2018, 18, 1069-1076. [CrossRef] [PubMed]

12. Cooper, E.H. The biology of cell death in tumours. Cell Tissue Kinet. 1973, 6, 87-95. [CrossRef] [PubMed]

13. Elmore, S. Apoptosis: A review of programmed cell death. Toxicol. Pathol. 2007, 35, 495-516. [CrossRef] [PubMed]

14. Kaufmann, S.H.; Earnshaw, W.C. Induction of apoptosis by cancer chemotherapy. Exp. Cell Res. 2000, 256, 42-49. [CrossRef] [PubMed]

15. Guzik, T.J.; Harrison, D.G. Vascular NADPH oxidases as drug targets for novel antioxidant strategies. Drug Discov. Today 2006, 11, 524-533. [CrossRef]

16. Fulda, S. Targeting apoptosis for anticancer therapy. Semin. Cancer Biol. 2015, 31, 84-88. [CrossRef] [PubMed]

17. Chiba, T.; Kamiya, A.; Yokosuka, O.; Iwama, A. Cancer stem cells in hepatocellular carcinoma: Recent progress and perspective. Cancer Lett. 2009, 286, 145-153. [CrossRef]

18. Lee, G.; Hall, R.R.; Ahmed, A.U. Cancer stem cells: Cellular plasticity, niche, and its clinical relevance. J. Stem Cell Res. Ther. 2016, 6, 363. [CrossRef]

19. Jordan, C.T.; Guzman, M.L.; Noble, M. Cancer stem cells. N. Engl. J. Med. 2006, 355, 1253-1261. [CrossRef]

20. Vu, N.B.; Nguyen, T.T.; Tran, L.C.D.; Do, C.D.; Nguyen, B.H.; Phan, N.K.; Pham, P.V. Doxorubicin and 5-fluorouracil resistant hepatic cancer cells demonstrate stem-like properties. Cytotechnology 2013, 65, 491-503. [CrossRef]

21. Nio, K.; Yamashita, T.; Kaneko, S. The evolving concept of liver cancer stem cells. Mol. Cancer 2017, 16, 4. [CrossRef] [PubMed]

22. Millimouno, F.M.; Dong, J.; Yang, L.; Li, J.; Li, X. Targeting apoptosis pathways in cancer and perspectives with natural compounds from mother nature. Cancer Prev. Res. 2014, 7, 1081-1107. [CrossRef]

23. Shin, H.J.; Han, J.M.; Choi, Y.S.; Jung, H.J. Pterostilbene suppresses both cancer cells and cancer stem-like cells in cervical cancer with superior bioavailability to resveratrol. Molecules 2020, 25, 228. [CrossRef]

24. Andrighetti-Fröhner, C.R.; Antonio, R.V.; Creczynski-Pasa, T.B.; Barardi, C.R.M.; Simões, C.M.O. Cytotoxicity and potential antiviral evaluation of violacein produced by Chromobacterium violaceum. Mem. Inst. Oswaldo Cruz 2003, 98, 843-848. [CrossRef]

25. Alshatwi, A.A.; Subash-Babu, P.; Antonisamy, P. Violacein induces apoptosis in human breast cancer cells through up regulation of BAX, p53 and down regulation of MDM2. Exp. Toxicol. Pathol. 2016, 68, 89-97. [CrossRef]

26. Carvalho, D.D.; Costa, F.T.M.; Duran, N.; Haun, M. Cytotoxic activity of violacein in human colon cancer cells. Toxicol. In Vitro 2006, 20, 1514-1521. [CrossRef]

27. Ferreira, C.V.; Bos, C.L.; Versteeg, H.H.; Justo, G.Z.; Durán, N.; Peppelenbosch, M.P. Molecular mechanism of violacein-mediated human leukemia cell death. Blood 2004, 104, 1459-1464. [CrossRef]

28. Scchmitz, K.J.; Wohlschlaeger, J.; Lang, H.; Sotiropoulos, G.C.; Malago, M.; Steveling, K.; Reis, H.; Cicinnati, V.R.; Schmid, K.W.; Baba, H.A. Activation of the ERK and AKT signalling pathway predicts poor prognosis in hepatocellular carcinoma and ERK activation in cancer tissue is associated with hepatitis C virus infection. J. Hepatol. 2008, 48, 83-90. [CrossRef] [PubMed]

29. Kim, S.M.; Han, J.M.; Le, T.T.; Sohng, J.K.; Jung, H.J. Anticancer and antiangiogenic activities of novel $\alpha$-mangostin glycosides in human hepatocellular carcinoma cells via downregulation of c-Met and HIF-1 $\alpha$. Int. J. Mol. Sci. 2020, 21, 4043. [CrossRef] [PubMed]

30. Shih, P.C.; Mei, K.C. Role of STAT3 signaling transduction pathways in cancer stem cell-associated chemoresistance. Drug Discov. Today 2021, 56, 1450-1458. [CrossRef]

31. Ma, S.; Lee, T.K.; Zheng, B.J.; Chan, K.W.; Guan, X.Y. CD133+ HCC cancer stem cells confer chemoresistance by preferential expression of the Akt/PKB survival pathway. Oncogene 2008, 27, 1749-1758. [CrossRef]

32. Chen, H.A.; Kuo, T.C.; Tseng, C.F.; Ma, J.T.; Yang, S.T.; Yen, C.J.; Yang, C.Y.; Sung, S.Y.; Su, J.L. Angiopoietin-like protein 1 antagonizes MET receptor activity to repress sorafenib resistance and cancer stemness in hepatocellular carcinoma. Hepatology 2016, 64, 1637-1651. [CrossRef]

33. Tsuruo, T.; Naito, M.; Tomida, A.; Fujita, N.; Mashima, T.; Sakamoto, H.; Haga, N. Molecular targeting therapy of cancer: Drug resistance, apoptosis and survival signal. Cancer Sci. 2003, 94, 15-21. [CrossRef]

34. Lan, X.; Wu, Y.Z.; Wang, Y.; Wu, F.R.; Zang, C.B.; Tang, C.; Cao, S.; Li, S.L. CD133 silencing inhibits stemness properties and enhances chemoradiosensitivity in CD133-positive liver cancer stem cells. Int. J. Mol. Med. 2013, 31, 315-324. [CrossRef]

35. Ma, S.; Chan, K.W.; Hu, L.; Lee, T.K.W.; Wo, J.Y.H.; Ng, I.O.L.; Zheng, B.J.; Guan, X.Y. Identification and characterization of tumorigenic liver cancer stem/progenitor cells. Gastroenterology 2007, 132, 2542-2556. [CrossRef] [PubMed]

36. Barclay, W.W.; Axanova, L.S.; Chen, W.; Romero, L.; Maund, S.L.; Soker, S.; Lees, C.J.; Cramer, S.D. Characterization of adult prostatic progenitor/stem cells exhibiting self-renewal and multilineage differentiation. Stem Cells 2008, 26, 600-610. [CrossRef] [PubMed]

37. Tomita, H.; Tanaka, K.; Tanaka, T.; Hara, A. Aldehyde dehydrogenase 1A1 in stem cells and cancer. Oncotarget 2016, 7, 11018-11032. [CrossRef] [PubMed]

38. Ghoshal, S.; Fuchs, B.C.; Tanabe, K.K. STAT3 is a key transcriptional regulator of cancer stem cell marker CD133 in HCC. Hepatobiliary Surg. Nutr. 2016, 5, 201-203. [CrossRef] [PubMed] 
39. Sun, C.; Sun, L.; Jiang, K.; Gao, D.M.; Kang, X.N.; Wang, C.; Zhang, S.; Huang, S.; Qin, X.; Li, Y.; et al. NANOG promotes liver cancer cell invasion by inducing epithelial-mesenchymal transition through NODAL/SMAD3 signaling pathway. Int. J. Biochem. Cell Biol. 2013, 45, 1099-1108. [CrossRef] [PubMed]

40. Huang, P.; Qiu, J.; Li, B.; Hong, J.; Lu, C.; Wang, L.; Wang, J.; Hu, Y.; Jia, W.; Yuan, Y. Role of Sox2 and Oct4 in predicting survival of hepatocellular carcinoma patients after hepatectomy. Clin. Biochem. 2011, 44, 582-589. [CrossRef] 